\title{
Health-Related Quality of Life of People with Physical Disability in South-South, Nigeria
}

\author{
Andrew-Essien N. E. and Ojule I. N. \\ Department of Preventive and Social Medicine, College of Health Sciences, University of Port Harcourt \\ Corresponding author: Ojule I. N.; inumanye.ojule@uniport.edu.ng
}

Received: 16 October 2020;

Accepted: 15 November 2020;

Published: 21 November 2020

\begin{abstract}
Background: The global increase in non-communicable diseases and increased aging of most populations is projected to have a profound effect on the overall prevalence of disability. Quality of life is a concept that has become fundamental to assessing life and living of all individuals more so for people with disabilities. In this study, we focused on assessing the quality of life of persons with mobility disabilities in Rivers State, Nigeria, identifying factors that influence their quality of life from their perspective. Materials and Methods: A descriptive, cross-sectional design was used in conducting this study among 179 subjects with a physical disability, specifically mobility impairment. The inclusion criterion was all persons with a physical disability. Exclusion criteria were children (0-17 years) with any form of disability, persons with intellectual, visual and hearing impairments. We used a Two-Stage sampling process using a computerized random number generator.

The study tool was the (7) WHOQOL - BREF questionnaire which was both self and interviewer-administered. Data were analyzed using both descriptive and inferential statistics. Significance was set at $\mathrm{P} \leq 0.05$. Results: The lowest and the highest mean scores of WHOQOL-BREF domains were found for the social relationships domain (Mean $=10.58)$ and the environmental health domain $(M e a n=23.52)$, respectively. The mean age of respondents was $38.49 \pm 10.89$ years. Respondents $\leq 34$ years of age had a higher mean overall QoL scores $(2.71 \pm 1.04)$ than those above 34 years $(2.57 \pm 1.10)$. A significance was observed between age and physical health. Education years was significantly associated with two domains (psychological and environment), Employment status was associated with two domains (psychological and social relationships), and the onset of disability associated with the psychological domain $(\mathrm{p}<0.05)$. Conclusion: Quality of life was relatively low across the four health-related domains, with the social relationship domain recording the lowest mean QoL scores. The factors that had significant positive relationships with various domains of quality of life were level of education, gender, age, occupation and activities of daily living. In Nigeria, disability status is still largely absent from routine data collection. This study adds to bridging the gap in evidence-based research on disability.
\end{abstract}

\section{Keywords: Quality-of-life, disability, Nigeria}

\section{Introduction}

Disability, by definition, is the umbrella term for impairments, activity limitations and participation restrictions, as imposed by society when a person with a physical, psychosocial, intellectual, neurological and/or sensory impairment lacks access to full participation in all aspects of life, and when society fails to uphold the rights and specific needs of individuals with impairments ${ }^{[1]}$.

Persons with disabilities are heterogeneous and diverse with disabilities ranging from visible to invisible, temporary to long term, static to episodic, minor to severe. Categories of disability include, physical, sensory, intellectual, cognitive and emotional disabilities. In describing physical disability using gross anatomy, we have hearing, visual, speech, visceral and mobility impairment.

Physical disabilities are conditions that interfere with or limit social functioning and are stress additives that involve difficulties in basic daily activities ${ }^{[2]}$. Patla and colleagues ${ }^{[3]}$ defined Mobility disability as occurring "when impairments in mobility restrict the ability of individuals to move about in their natural environment as they carry out activities essential to daily life." Mobility disability is caused by different factors and can begin at any stage in life. It arises commonly from complications of communicable and non-communicable disorders, trauma, natural ageing, congenital deformities, etc. The global increase in noncommunicable diseases and emerging aging of most populations is projected to have a profound effect on the overall prevalence of disability ${ }^{[4]}$.

A report of the Spatial Patterns of Disability in Nigeria showed that the northeast and northwest regions have the greatest burden of disability arising from vision impairment $(12.42-18.74$ persons per 1000), while disability due to mobility which ranges between 2.06 and 5.46 per 1000 shows an eastly pattern ${ }^{[5]}$.

Quality of life is a concept that has become fundamental to assessing the life and living of all individuals. There has been an increasing call for clinicians and researchers to always assess the QOL of their clients. This practice, especially when self-reported by he client themselves, will demonstrate how the clients feel, how they perceive the health care and support they receive. It also opens 
a window of opportunity to identify abuse and mistreatment of the disabled person which is a common phenomenon worldwide ${ }^{[6]}$.

Quality of life covers different aspects of life usually as the assessor perceives it and the concept has continued to evolve. According to the WHO Quality of Life -BREF ${ }^{[7]}$ (WHOQOLBREF, 2004), "Quality of life is defined as individuals' perceptions of their position in life in the context of the culture and value systems in which they live and in relation to their goals, expectations, standards and concerns. The public health view of Quality of life comprises acceptable levels of physical and mental functioning of the individual in order to maintain a reasonable independent social role ${ }^{[8,9]}$.

A focused group ${ }^{[8]}$ discussion stated that people living with disabilities appreciate many of the same values considered important by the general public. The above group affirmed the importance of recognising the distinctive perceptions, cultural behaviours, as well as knowledge and insights persons with disability have of themselves when measuring their quality of life.

African researchers have noted that people with disabilities are not yet experiencing meaningful improvement in their quality of life, equal rights and a good level of community integration according to a southern Africa survey. Mitra, Posarac, \& Vick ${ }^{[10]}$ also observed that there is a substantial gap in access to services, and a systematic pattern of lower levels of living amongst individuals with a disability as compared to their non-disabled counterparts. Key indicators on education, physical health, employment, socioeconomic status, access to information and social participation all point in the same direction ${ }^{[11]}$. Real change and social development are required to realize a truly inclusive society ${ }^{[12]}$.

According to Amusat and colleagues ${ }^{[13]}$, several efforts to embed disability in the development agenda in Africa has not been easy and all the net-workings have not yielded a lot of the expected results. This has been blamed on poor resources and lack of commitment on the part of governments. In the Nigerian context, this has also been largely affected by lack of quality data as there is need for essential scientific evidence to promote policy change and intervention. In Nigeria, persons with disabilities continue to constitute one of the poorest, socially excluded and marginalized groups within the society ${ }^{[14]}$. Another Nigerian study noted that 9 out of 10 persons with disabilities in Nigeria live below the poverty line ${ }^{[15]}$. By ratifying the United Nations Conventions on Right of Persons with Disability and its optional protocol, the Nigerian government affirmed full participation in the disability agenda of the United Nations but in reality, Nigerians with disabilities are still faced with challenges, as have been enumerated earlier. This results in distortion of activities of daily living and quality of life of people with disabilities. Even though individuals react in different ways to disabling conditions, such as stigmatization, discrimination, shame, fear and exclusion from family or community life, the narrative easily available is mostly derived from the perspective of society. These persons are also generally vulnerable by virtue of negative societal attitudes, neglect and general lack of insight by even persons with disabilities themselves. In this study, we focused on assessing the quality of life of persons with a mobility disability, shedding light on factors that influence their quality of life from their own perspective.

\section{Materials and Methods}

\section{Study Area}

Rivers State has a total area of $11,077 \mathrm{~km}^{2}$, making it the 26th largest state in Nigeria with 23 Local Government Areas.
According to the 2006 census, Rivers State is inhabited by $5,198,716$ people. The current estimate stands at over 7 million people. It has young demography with $61 \%$ of its population between the ages of 15 to 65 years ${ }^{[16]}$.

\section{Study Design}

This was a cross-sectional descriptive study.

\section{Study Population}

The study population was made up of male and female persons with a physical disability, specifically mobility impairment in Rivers State. The inclusion criterion was all persons with physical disabilities in Rivers State. Exclusion criteria were children (0-17 years) with any form of disability, persons with intellectual, visual and hearing impairments. Persons with a mobility disability who were severely ill were all excluded.

\section{Sampling Method}

To ensure that all persons with mobility disabilities in Rivers State had an equal opportunity to participate in the research we used a Two-Stage sampling process using a computerized random number generator.

In Stage 1 of the sampling method, we did Simple Random Sampling. All the Local Government Areas in Rivers State served as the sampling frame, where each Local Government Area was assigned a number. Using a random number generator App, we selected ten local government areas out of the twenty-three.

In Stage 2 of sampling, we also used Simple Random Sampling Process. In each selected Local Government Area, through the Coordinators of the Disabled persons' organisation and the Local government Council, a list of registered persons with physical disability was obtained. This served as another sampling frame. Numbers were assigned and using a random number generator App we carried out simple random sampling and engaged the participants.

\section{Study Instrument}

Study Instrument/Tool-1: Structured Questionnaire

Section A: Socio-demographic Data and Background Information

Section B: Disability Status

Study Instrument/Tool - 2: WHOQOL - BREF Questionnaire

Section C: Quality of Life (QOL)

The Structured Questionnaires had 3 sections. The first section covered information on Socio-demographics like gender, age, occupation and education. The second section focused on the disability status, - type of disability, onset of disability, and caregivers. The third section was the ${ }^{[7]}$ WHOQOL-BREF questionnaire which focused on quality of life, health and the four domains of quality of life.

WHOQOL is an assessment of a multi-dimensional concept incorporating the individual's perception of health status, psycho-social status and other aspects of life ${ }^{[7]}$. WHOQOL-BREF comprises 26 items and is used to multi-dimensionally assess the quality of life. It measures Quality of Life by encompassing four health-related domains: Domain one (physical health) has seven (7) items, domain two (psychological health) has five (5) items, domain three (social relationships) has three (3) items and domain four (environmental) has eight (8) items, as well as two general 
questions on self-assessment of overall health and overall Quality of Life. Each of these domains is rated on a 5-point Likert scale.

The score for each subscale is the total score of the constituting items. Higher scores on each subscale indicate better ratings. For more consistency, Cronbach alpha of WHO QOL BREF was reported to be 0.70 to 0.77 for the four domains ${ }^{[17]}$.

The WHOQOL-BREF was developed as a cross-culturally applicable measure of subjective quality of life. It arose from years of developmental research on Quality of Life and health care. It is person-centered and designed for broad use and so enables assessment of a wide range of diseases and conditions ${ }^{[18]}$. For its brevity, yet comprehensive measure of Quality of Life, [7] WHOQOL-BREF has proven reliable in epidemiological studies as well as in intervention studies ${ }^{[19]}$.

For this work, four health-related domains were employed, viz; Physical health domain, which comprises activities of daily living, dependence on medicinal substances and medical aids, energy and fatigue, mobility, pain and discomfort, sleep and rest, and work capacity; Psychological domain, which covers bodily image and appearance, negative feelings, positive feelings, selfesteem, spirituality, religion, and personal beliefs, thinking, learning, memory, and concentration; Social relationships domain which includes personal relationships, social support, and sexual activity. The environment domain contains financial resources, freedom, physical safety and security, health and social care. Other parts of environmental domain are accessibility and quality, home environment, opportunities for acquiring new information and skills, participation in and opportunities for recreation and leisure activities, physical environment (pollution, noise, traffic, climate), and transport.

The Study Instrument/Tool 1 was a self or interviewer administered Questionnaire in English language. Where we encountered challenges with communication, an interpreter from the community assisted. However, for most participants a simple rephrase in Pidgin English was adequate.

\section{Study procedure/Data collection process}

In order to ensure that data collection was smooth, five research assistants were engaged for the purpose of collecting primary data from persons with physical disability in different local government

Table 1: Socio-demographic Data

\begin{tabular}{|c|l|l|}
\hline Characteristics & $\begin{array}{l}\text { Frequency } \\
\mathbf{n = 1 7 9}\end{array}$ & Percentage (\%) \\
\hline Age(years) & & 7.26 \\
\hline $18-24$ & 13 & 10.06 \\
\hline $25-29$ & 18 & 21.23 \\
\hline $30-34$ & 38 & 22.35 \\
\hline $35-39$ & 40 & 15.64 \\
\hline $40-44$ & 28 & 8.94 \\
\hline $45-49$ & 16 & 6.15 \\
\hline $50-54$ & 11 & 2.23 \\
\hline $55-59$ & 4 & 3.35 \\
\hline $60-64$ & 6 & 2.79 \\
\hline$\geq 65$ & 5 & \\
\hline Mean Age & $\mathbf{3 8 . 4 9}$ & \\
\hline Gender & & \\
\hline Male & 110.89 years & 65.92 \\
\hline Female & 61 & 34.08 \\
\hline Marital Status & & \\
\hline Single & 95 & 53.07 \\
\hline Warried & 70 & 39.11 \\
\hline Separated & 6 & 3.35 \\
\hline Divorced & 5 & 2.79 \\
\hline & 3 & 1.68 \\
\hline
\end{tabular}

areas of Rivers State. The questionnaires were either self or interviewer administered.

A training of the research assistants on the questionnaire to be used was done after which they engaged in role play to master the use of the tool.

A pre-test was carried out in Akwa-Ibom state. The reason for this choice is that both states are contiguous and demographically related.

\section{Data Analysis}

Descriptive statistics was used to analyse data which were expressed as frequencies, percentages, means and standard deviations.

The (7) WHOQOL-BREF has four domains and scores for each domain were computed.

There were also two items that were examined separately: an individual's overall perception of quality of life and overall perception of health.

Inferential statistical tools were employed to assess relationships between Socio-demographic variables and quality of life. Data was analysed using Chi-squared test, Student t-test and ANOVA, where appropriate. Significance was set at $\mathrm{P} \leq 0.05$. Data was analysed using SPSS version 20.

\section{Ethical Considerations}

Ethical clearance was obtained from the Research Ethics committee of the University of Port Harcourt. Written permission was obtained from the World Health Organization for use of the WHOQOL tool. Participants were all given written and verbal information on the study, explaining the objectives of the study, after which they were asked to sign a written Informed Consent statement. Those that had no signature were asked to thumb-print the consent forms.

Anonymity and confidentiality were ensured as no names were taken during the questionnaire administration. The participants were simply identified with numbers.

\section{Results}




\begin{tabular}{|c|l|l|}
\hline Education & & \\
\hline Never went to School & 11 & 6.15 \\
\hline Primary & 39 & 21.79 \\
\hline Secondary & 83 & 46.37 \\
\hline Tertiary & 46 & 25.70 \\
\hline Employment status & & \\
\hline Self employed & 90 & 50.28 \\
\hline Unemployed & 52 & 29.05 \\
\hline Private sector & 21 & 11.73 \\
\hline Civil servant & 12 & 6.70 \\
\hline Professional & 3 & 1.68 \\
\hline Retired & 1 & 0.56 \\
\hline Who do you live with? & 36 & 20.11 \\
\hline Nuclear family & & \\
\hline Extended family & 128 & 71.51 \\
\hline
\end{tabular}

Table 2: Onset of Disability

\begin{tabular}{|l|l|l|}
\hline Characteristics & $\begin{array}{l}\text { Frequency } \\
\mathbf{n = 1 7 9}\end{array}$ & Percentage (\%) \\
\hline Onset of Disability & & 57.54 \\
\hline Childhood & 103 & 31.84 \\
\hline Adulthood & 57 & 6.15 \\
\hline Teenager & 11 & 4.47 \\
\hline Birth & 8 & \\
\hline
\end{tabular}

Table 3: Quality of Life (rated on a 5-point Likert scale)

\begin{tabular}{|l|l|l|}
\hline QoL Domain & $\begin{array}{l}\text { Mean } \\
\mathbf{n = 1 7 9}\end{array}$ & SD \\
\hline $\begin{array}{l}\text { Overall Quality of Life } \\
\text { (Single item) }\end{array}$ & 2.63 & 1.08 \\
\hline $\begin{array}{l}\text { Overall Health perception } \\
\text { (Single item) }\end{array}$ & 1.16 & 1.08 \\
\hline Physical Health (7 items) & 23.07 & 3.50 \\
\hline Psychological (5 items) & 20.40 & 4.50 \\
\hline Social Relationships (3 items) & 10.58 & 2.04 \\
\hline Environment (8 items) & 23.52 & 4.60 \\
\hline
\end{tabular}

Table 4: Association between Socio-demographic characteristics and Quality of Life

\begin{tabular}{|c|c|c|c|}
\hline \multirow[t]{2}{*}{ QoL Domain } & \multicolumn{2}{|l|}{ Gender } & \multirow[t]{2}{*}{ t-test (p-value) } \\
\hline & $\begin{array}{l}\text { Male } \\
\text { Mean } \pm \text { SD }\end{array}$ & $\begin{array}{l}\text { Female } \\
\text { Mean } \pm \text { SD }\end{array}$ & \\
\hline $\begin{array}{l}\begin{array}{l}\text { Overall Quality of Life } \\
\text { (Single item) }\end{array} \\
\end{array}$ & $2.50 \pm 1.08$ & $2.87 \pm 1.06$ & $2.19(0.03)^{*}$ \\
\hline $\begin{array}{l}\text { Overall Health perception } \\
\text { (Single item) }\end{array}$ & $2.82 \pm 1.08$ & $2.98 \pm 1.09$ & $0.95(0.34)$ \\
\hline Physical Health & $23.24 \pm 3.19$ & $22.75 \pm 4.03$ & $0.88(0.383)$ \\
\hline Psychological & $20.17 \pm 4.57$ & $20.84 \pm 4.37$ & $0.94(0.349)$ \\
\hline Social Relationships & $10.74 \pm 3.49$ & $10.26 \pm 2.32$ & $1.48(0.140)$ \\
\hline \multirow[t]{3}{*}{ Environment } & $23.69 \pm 4.46$ & $23.20 \pm 4.88$ & $0.67(0.501)$ \\
\hline & \multicolumn{2}{|l|}{ Age } & \\
\hline & $\begin{array}{l}\leq 34 \text { years } \\
\text { Mean } \pm \mathrm{SD}\end{array}$ & $\begin{array}{l}>\mathbf{3 4} \text { years } \\
\text { Mean } \pm \mathrm{SD}\end{array}$ & \\
\hline $\begin{array}{l}\text { Overall Quality of Life } \\
\text { (Single item) }\end{array}$ & $2.71 \pm 1.04$ & $2.57 \pm 1.10$ & $0.83(0.409)$ \\
\hline $\begin{array}{l}\text { Overall Health perception } \\
\text { (Single item) }\end{array}$ & $2.78 \pm 0.97$ & $2.94 \pm 1.14$ & $0.93(0.355)$ \\
\hline Physical Health & $23.72 \pm 3.24$ & $22.66 \pm 3.60$ & $1.94(0.05)^{*}$ \\
\hline Psychological & $20.93 \pm 3.72$ & $20.06 \pm 4.91$ & $1.25(0.212)$ \\
\hline Social Relationships & $10.75 \pm 1.87$ & $10.46 \pm 2.14$ & $0.93(0.356)$ \\
\hline \multirow[t]{3}{*}{ Environment } & $23.38 \pm 4.66$ & 23.61 & $0.33(0.743)$ \\
\hline & \multicolumn{2}{|c|}{ Educational Status } & \\
\hline & $\begin{array}{l}\leq \text { Secondary } \\
\text { Mean } \pm \text { SD }\end{array}$ & $\begin{array}{l}\text { Tertiary } \\
\text { Mean } \pm \text { SD }\end{array}$ & \\
\hline
\end{tabular}




\begin{tabular}{|l|l|l|l|}
\hline $\begin{array}{l}\text { Overall Quality of Life } \\
\text { (Single item })\end{array}$ & $2.43 \pm 1.09$ & $3.20 \pm 0.83$ & $4.35(0.001)^{*}$ \\
\hline $\begin{array}{l}\text { Overall Health perception } \\
\text { (Single item })\end{array}$ & $2.72 \pm 1.02$ & $3.33 \pm 1.14$ & $3.37(0.001)^{*}$ \\
\hline & & & \\
\hline Physical Health & $22.92 \pm 3.57$ & $23.52 \pm 3.27$ & $1.01(0.314)$ \\
\hline Psychological & $19.95 \pm 4.65$ & $21.67 \pm 3.78$ & $2.26(0.03)^{*}$ \\
\hline Social Relationships & $10.60 \pm 2.04$ & $10.50 \pm 2.05$ & $0.29(0.772)$ \\
\hline Environment & $22.92 \pm 4.41$ & $25.26 \pm 4.74$ & $3.05(0.003)^{*}$ \\
\hline
\end{tabular}

*Statistically significant $(p \leq 0.05)$

\section{Quality of life and Gender}

A statistically significant difference was observed between respondents' gender and overall quality of life, as females had higher mean QoL scores compared to males (2.87 vs. 2.50; $\mathrm{p}=0.03$ ). The scores for the overall health perception of the respondents and the four QoL domains of both genders did not differ significantly as $\mathrm{p}>0.05$.

\section{Quality of life and Age}

A statistically significant difference was observed between respondents' Age and Physical Health QoL domain, as respondents $\leq 34$ years had a higher mean QoL score compared to those $>34$ years (23.72 vs. 22.66; $\mathrm{p}=0.05)$.

The overall QoL, overall health perception of the respondents and three QoL domains (Psychological, Social
Relationships, and Environment) of both age groups (above 34 years and below 34 years) did not differ significantly between the two age groups $(\mathrm{p}>0.05)$.

\section{Quality of life and Educational Status}

A statistically significant difference was observed between respondents' Educational status and overall QoL, overall health perception and two QoL domains (Psychological and Environment). Respondents with Tertiary education had a statistically significant higher mean overall QoL scores when compared with those with Secondary school education or less (3.20 vs. $2.43 ; \mathrm{p}=0.001$ ), overall health perception (3.33 vs. 2.72; $\mathrm{p}=0.001$ ), Psychological domain of QoL (21.67 vs. 19.95; $\mathrm{p}=0.03$ ) and Environment domain of QoL (25.26 vs. 22.92; $\mathrm{p}=0.003$ ).

Table 5: Association between Socio-demographic characteristics and Quality of Life

\begin{tabular}{|l|l|l|l|}
\hline QoL Domain & Marital Status & t-test (p-value) \\
\hline & $\begin{array}{l}\text { Married } \\
\text { Mean } \pm \text { SD }\end{array}$ & $\begin{array}{l}\text { Single } \\
\text { Mean } \pm \text { SD }\end{array}$ & \\
\hline & & & $0.96(0.337)$ \\
\hline $\begin{array}{l}\text { Overall Quality of Life } \\
\text { Single item) }\end{array}$ & $2.53 \pm 1.16$ & $2.69 \pm 1.02$ & $0.09(0.932)$ \\
\hline $\begin{array}{l}\text { Overall Health perception } \\
\text { Single item) }\end{array}$ & $2.89 \pm 1.11$ & $2.87 \pm 1.06$ & \\
\hline & & & $0.21(0.830)$ \\
\hline Physical Health & & $23.03 \pm 3.57$ & $0.42(0.678)$ \\
\hline Psychological & $23.14 \pm 3.41$ & $20.28 \pm 4.33$ & $2.89(0.0004)^{*}$ \\
\hline Social Relationships & $20.57 \pm 22.83$ & $10.23 \pm 2.07$ & $0.08(0.937)$ \\
\hline Environment & $11.11 \pm 1.88$ & $23.54 \pm 4.57$ & \\
\hline
\end{tabular}

*Statistically significant $(p \leq 0.05)$

\section{Quality of life and Marital Status}

A statistically significant difference was observed between respondents' Marital Status and Social Relationships domain of
QoL, as Married respondents had a higher mean QoL score compared to those who were single (11.11 vs. 10.23 ; $\mathrm{p}=0.0004$ ). The overall QoL and health perception of the respondents did not differ significantly between the singles and the married.

Table 6: Association between Socio-demographic characteristics and Quality of Life

\begin{tabular}{|l|l|l|l|l|}
\hline QoL Domain & Employment status & ANOVA (p-value) \\
\hline & $\begin{array}{l}\text { Government/Private Employee } \\
\text { Mean } \pm \text { SD }\end{array}$ & $\begin{array}{l}\text { Self Employed } \\
\text { Mean } \pm \text { SD }\end{array}$ & $\begin{array}{l}\text { Unemployed } \\
\text { Mean } \pm \text { SD }\end{array}$ & \\
\hline $\begin{array}{l}\text { Overall Quality of Life } \\
\text { Single item })\end{array}$ & $2.83 \pm 0.97$ & $2.69 \pm 1.09$ & $2.38 \pm 1.11$ & $2.25(0.109)$ \\
\hline $\begin{array}{l}\text { Overall Health perception } \\
\text { Single item })\end{array}$ & $3.0 \pm 1.12$ & $2.99 \pm 1.04$ & $2.60 \pm 1.08$ & $2.46(0.09)$ \\
\hline Physical Health & & & & \\
\hline Psychological & $23.69 \pm 3.34$ & $23.28 \pm 3.30$ & $22.30 \pm 3.85$ & $2.03(0.134)$ \\
\hline Social Relationships & $21.08 \pm 4.88$ & $20.99 \pm 3.90$ & $18.92 \pm 4.91$ & $4.18(0.02)^{*}$ \\
\hline Environment & $11.42 \pm 2.16$ & $10.39 \pm 1.79$ & $10.32 \pm 2.23$ & $3.98(0.02)^{*}$ \\
\hline & $24.56 \pm 4.33$ & $23.27 \pm 4.48$ & $23.25 \pm 4.95$ & $1.14(0.320)$ \\
\hline & & & & \\
\hline & Subjects living with: & $\begin{array}{l}\text { Extended Family } \\
\text { Mean } \pm \text { SD }\end{array}$ & $\begin{array}{l}\text { Nuclear Family } \\
\text { Mean } \pm \text { SD }\end{array}$ \\
\hline $\begin{array}{l}\text { Overall Quality of Life } \\
\text { Single item })\end{array}$ & $\begin{array}{l}\text { Alone } \\
\text { Mean } \pm \text { SD }\end{array}$ & $2.92 \pm 0.87$ & $2.50 \pm 0.76$ & $1.62(0.200)$ \\
\hline Overall Health perception & $3.14 \pm 1.05$ & $2.64 \pm 1.01$ & $2.84 \pm 1.09$ & $1.49(0.23)$ \\
\hline
\end{tabular}




\begin{tabular}{|l|l|l|l|l|}
\hline (Single item) & & & & \\
\hline & & & & \\
\hline Physical Health & $23.22 \pm 4.33$ & $22.57 \pm 2.56$ & $23.14 \pm 3.30$ & $0.191(0.826)$ \\
\hline Psychological & $20.69 \pm 4.22$ & $20.71 \pm 2.49$ & $20.35 \pm 4.70$ & $0.109(0.897)$ \\
\hline Social Relationships & $10.11 \pm 2.27$ & $10.71 \pm 1.82$ & $10.72 \pm 1.97$ & $1.29(0.28)$ \\
\hline Environment & $23.36 \pm 5.23$ & $23.14 \pm 4.66$ & $23.68 \pm 4.38$ & $0.135(0.875)$ \\
\hline
\end{tabular}

*Statistically significant $(P \leq 0.05)$

\section{Quality of life and Employment status}

A statistically significant difference was observed between respondents' Employment status and the Psychological domain of QOL. There was also a statistically significant difference observed between employment status and Social Relationships domain of
QOL, but respondents who were gainfully employed either in the Public or Private Sector had a higher mean QOL score (21.08) compared to those who were Self-employed (20.99) and those who were unemployed (18.92). This association was also statistically significant in the Social relationship domain of QOL.

Table 7: Association between onset of disability and Quality of Life

\begin{tabular}{|c|c|c|c|c|c|c|}
\hline Onset of & Quality of Life Domai & & & & & \\
\hline & $\begin{array}{l}\text { Overall Quality of } \\
\text { Life (Single item) }\end{array}$ & $\begin{array}{l}\text { Overall Health perception } \\
\text { (Single item) }\end{array}$ & $\begin{array}{l}\text { Physical } \\
\text { Health } \\
\end{array}$ & Psychological & $\begin{array}{l}\text { Social } \\
\text { Relationships } \\
\end{array}$ & Environmental \\
\hline & Mean \pm SD & Mean \pm SD & Mean \pm SD & Mean \pm SD & Mean \pm SD & Mean \pm SD \\
\hline Birth & $2.50 \pm 1.07$ & $3.25 \pm 0.89$ & $22.50 \pm 2.20$ & $20.13 \pm 2.17$ & $11.13 \pm 1.81$ & $23.50 \pm 4.84$ \\
\hline Childhood & $2.75 \pm 1.10$ & $2.92 \pm 1.13$ & $23.35 \pm 3.25$ & $21.29 \pm 3.63$ & $10.57 \pm 1.94$ & $23.60 \pm 4.57$ \\
\hline Teenage & $2.38 \pm 0.98$ & $2.74 \pm 0.99$ & $22.33 \pm 4.06$ & $18.60 \pm 5.39$ & $\mathrm{c} 10.49 \pm 2.31$ & $22.96 \pm 4.63$ \\
\hline Adulthood & $2.91 \pm 1.30$ & $2.91 \pm 0.99$ & $24.73 \pm 4.06$ & $21.55 \pm 5.70$ & $10.64 \pm 2.31$ irth & $25.64 \pm 4.63$ \\
\hline $\begin{array}{l}\text { ANOVA } \\
(p-\text { value })\end{array}$ & $\begin{array}{l}1.83 \\
(0.143)\end{array}$ & $\begin{array}{l}0.67 \\
(0.554)\end{array}$ & $\begin{array}{l}1.99 \\
(0.117)\end{array}$ & $\begin{array}{l}4.96 \\
(0.003) *\end{array}$ & $\begin{array}{l}0.23 \\
(0.87)\end{array}$ & $\begin{array}{l}1.06 \\
(0.379)\end{array}$ \\
\hline
\end{tabular}

*Statistically significant $(p \leq 0.05)$

\section{Quality of Life and Onset of Disability}

A statistically significant association was observed between the onset of disability and the Psychological domain, as respondents whose disabilities started in the adult age, had a higher mean QoL for psychological domain $(21.55 \pm 5.70 ; \mathrm{p}=0.003)$.

No statistically significant association was observed between the onset of disability and overall Quality of life, overall health perception, physical health, social relationships, and Environmental domain.

\section{Discussion}

\section{Quality of life and gender}

The male and female respondents differed significantly in overall quality of life, as females had a higher mean QoL scores compared to males. The findings of more female respondents having a higher mean quality of life scores is in contrast to a study by ${ }^{[20]}$ Murtagh $\&$ Hubert, who reported lower quality of life for women and who, explaining further the higher levels of functional disability and mobility limitations among women that contributed substantially to gender differences in disability and also to quality of life among aging men and women. The contrast in the findings can be explained by the difference in the mean age of the study subjects, as ours was a younger population. With age, women have been reported to have a greater prevalence of disabling conditions ${ }^{[21]}$. In our study, the scores of male and female subjects did not differ significantly across the domains and this was similar to another Nigerian study by ${ }^{[22]}$ Kaka, Ogwumike \& Adeniyi, whose scores for male and female subjects did not differ significantly in all the domains (physical, psychological, social and environment).

\section{Quality of life and Educational Status}

In relating QoL and educational status of respondents, there was a significant difference between the respondent's educational status and overall QoL and overall health perception and across psychological and environment QoL domains. In our study, respondents with a tertiary level of education had a significantly higher mean overall QoL scores, overall health perception, psychological domain of QoL and environment domain of QoL, compared to those with secondary education or less.

In explaining the relationship between education and quality of life, ${ }^{[23]}$ Pawłowska-Cyprysia and colleagues, indicated that a lower quality of life is influenced by demographic factors, such as low levels of education which can be considered as main factors predicting the quality of life of people with a physical disability. The World Health Survey (WHS), reports from most of the countries showed people with disabilities had lower educational achievement, experienced lower employment and income than their counterparts without disabilities ${ }^{[10]}$. This study suggests that a higher level of education tend to equip people to achieve better health and a better quality of life.

Taking a closer look at education and the environment domain, our study noted that people with a higher level of education had a higher quality of life in the environmental domain due to increased participation levels in social relationships and work. This finding was corroborated by other studies ${ }^{[24,25]}$.

\section{Quality of life and Age}

The Quality of Life differed significantly between respondents' age and physical Health domain, as respondents aged $\leq 34$ years had a higher QoL in physical health compared to those $>34$ years. This is explained by the increasing health challenges that come with aging, hence younger respondents had a higher quality of life in the physical health domain when compared to those who were more than 34 years. With increasing age, health conditions remain one major factor that influences the quality of life. A study ${ }^{[26]}$ on disability and psychosocial outcomes in old age however contradicts our finding as they found increasing age to be positively associated with a self-perceived better quality of life, explaining further that there may be a positive progression of the quality of life. Age was not the disability paradox, but rather a lowering of standards as people aged as they surmount constraints and develop coping mechanisms. 


\section{Quality of life and Employment}

The quality of life of the participants differed significantly across the occupational categories. The overall quality of life score was lower for the unemployed and highest for those who were gainfully employed in either the private or public sector across all healthrelated QoL domains, including overall quality of life and overall health. This compared favorably with a report that showed that women with disabilities who were unemployed had a lower selfassessed QoL than employed women ${ }^{[27]}$.

A significant difference was observed between respondents' employment status and psychological domain and social relationships domain, as respondents who were gainfully employed either in the public or private sector had a higher mean QoL score compared to those who were self-employed and those who were unemployed. This may easily be explained by the fact that with employment comes, presumably, a steady flow of income to meet needs and improve one's outlook, as opposed to doing business that may not be predictable in its income flow. With gainful employment there is increased social and work participation which can explain the significance in the psychological and social domain. The significance can also be explained by the difficulty that persons with disabilities have in securing gainful employment, as was similarly reported in a review of studies carried out in Cameroon that found that having a physical disability made it difficult to participate in employment [28]

\section{Quality of life and Marital Status}

The Quality of Life scores of participants differed significantly with regards to respondents' marital status in the social relationship domain. Married respondents had a higher QoL compared to those who were single. Difficulties in relationships can be deduced from the fact that more respondents are single than are married. Respondents who were single reported that disability was main reason for remaining single. Overall $\mathrm{QoL}$ and health perception of the respondents did not differ significantly, whether single or married.

\section{Quality of Life and Onset of disability}

It was important to investigate if there was any relationship between onset of disability and quality of life. Such a relationship was established in the psychological domain of quality of life. It was observed that people with physical disability who had the onset of disability as adults had a higher quality of life in this domain while subjects with onset in their teenage years had the lowest mean QOL score in this domain. This can be explained by the fact that an adult may be able to cope better psychologically with a disability at adulthood than as a teenager who is in his very self-conscious and transitional years. In contrast, a study ${ }^{[29]}$ on adults with physical disability didn't find the age of onset of disability to have any effect on quality of life, whether at birth, childhood, teenage age or as an adult. This was also similar to a lifespan study ${ }^{[30]}$. Grist ${ }^{[29]}$ also studied adaptation capabilities among persons with disabilities found that quality of life increased with increased duration of disability.

\section{Conclusion}

Considering the findings of this study in comparison to findings from similar published studies, this study identified level of education, sex, age and occupation to significantly influence quality of life and concludes that the quality of life of persons with physical disabilities in Rivers State, Nigeria was relatively low.
This study provides insight into the Quality of life of people with physical disability from their own perceptive. Even though the quality of life was relatively low across the four domains, it was lowest in the social relationship domain. Among the factors that significantly had a positive relationship with various domains of quality of life were level of education, gender, age and occupation. Assessing and measuring the quality of life of patients and clients should be a foremost objective of every clinician and researcher. It is also important, both as a needs' assessment tool and as an outcome measure in health promotion interventions. In Nigeria, disability is still largely absent from data collection. This study adds to bridging the gap in evidence-based research on disability.

\section{Limitations of the Study}

The results of this study should be evaluated with the following limitations in view:

Data regarding quality of life was self-reported and based on selfperception. Misrepresentation is therefore possible.

The sample population only included people with physical disabilities who were mobility impaired. The clinical status of the participants was based on self-report and not confirmed by medical records or clinical examinations.

The lack of existing rigorous and comparable data and statistics was also a limitation.

\section{Authors' contributions}

All the authors collaborated in producing the work. Author AEN designed, did literature search and carried out the study. Author INO supervised. Authors INO and AEN together wrote up the manuscript. All authors read and approved the final manuscript.

\section{Competing interests}

Authors have declared that no competing interests exist.

\section{References}

[1] UNCRDP. Convention on the rights of persons with disabilities and optional protocol. New York: UN. (2006). Retrieved May 25, 2013, from http://www.un.org/disabilities/documents/convention/con voptprot-e.pdf

[2] Russell D. Living arrangements, social integration, and loneliness in later life: The case of physical disability. Journal of Health and Social Behavior. 2009 Dec;50(4):460-75.

[3] Patla AE, Shumway-Cook A. Dimensions of mobility: defining the complexity and difficulty associated with community mobility. Journal of Aging and Physical Activity. 1999 Jan 1;7(1):7-19.

[4] WHO \& World Bank. World report on disability. Geneva: WHO. (2011). Retrieved May 2, 2016, from http://www.who.int/disabilities/world_report/2011/report .pdf

[5] National Bureau of Statistics. (2016). Social Statistics Report. Nigeria: National Bureau of Statistics.

[6] Zheng QL, Tian Q, Hao C, Gu J, Lucas-Carrasco R, Tao JT, Liang ZY, Chen XL, Fang JQ, Ruan JH, Ai QX. The 
role of quality of care and attitude towards disability in the relationship between severity of disability and quality of life: findings from a cross-sectional survey among people with physical disability in China. Health and quality of life outcomes. 2014 Dec 1;12(1):25.

[7] World Health Organization. (2004). WHOQOL-BREF Instructions, Administration, Scoring and Generic Version of the Assessment. Geneva: WHO. Retrieved June 2, 2018, from www.biomedcentral.com/14712458/10/492

[8] Mattevi BS, Bredemeier J, Fam C, Fleck MP. Quality of care, quality of life, and attitudes toward disabilities: perspectives from a qualitative focus group study in Porto Alegre, Brazil. Revista Panamericana de Salud Pública. 2012;31:188-96.

[9] Vankova D. Conceptual and Methodological Approaches to Quality of Life-a public health perspective. Scripta Scientifica Salutis Publicae. 2016 Jan 6;1(2):7-13.

[10] Mitra S, Posarac A, Vick B. Disability and poverty in developing countries: a multidimensional study. World Development. 2013 Jan 1;41:1-8.

[11] Eide AH, Ingstad B. Disability and poverty-Reflections on research experiences in Africa and beyond. African Journal of Disability. 2013;2(1).

[12] Kachaje R, Dube K, MacLachlan M, Mji G. The African Network for Evidence-to-Action on Disability: A role player in the realisation of the UNCRPD in Africa. African Journal of Disability. 2014;3(2), 86-90.

[13] Amusat N. Disability care in Nigeria: The need for professional advocacy. African Journal of Physiotherapy and Rehabilitation Sciences. 2009;1(1):30-6.

[14] Haruna M. A. (2017). The Problem of Living with Disability in Nigeria. Journal of Law, Policy and Globalization, 65, 103-113. Retrieved July 4, 2018, from www.iiste.org

[15] Nigerian Institute of Advanced Legal Studies. (2010). Communique on Roundtable on the unserved handicapped: Raising respect and awareness for the rights of the disabled in Nigeria. Retrieved January 8, 2018 from nials-nigeria.org/round_tables/Communiq.

[16] Rivers State Government. Map of Rivers State (2018). Retrieved June 2, 2018, from https://riversstate.gov.ng

[17] The WHOQOL Group. The World Health Organization Quality of Life Assessment (WHOQOL): position paper from the World Health Organization. Social Science and Medicine. 1995; 41(10), 1403-1409.

[18] Skevington SM, Lotfy M, O'Connell KA. The World Health Organization's WHOQOL-BREF quality of life assessment: psychometric properties and results of the international field trial. A report from the WHOQOL group. Quality of life Research. 2004 Mar 1;13(2):299310.
[19] Hasanah CI, Naing L, Rahman AR. World Health Organization quality of life assessment: brief version in Bahasa Malaysia. Medical Journal of Malaysia. 2003 Mar 1;58(1):79-88.

[20] Murtagh KN, Hubert HB. Gender differences in physical disability among an elderly cohort. American journal of public health. 2004 Aug;94(8):1406-11.

[21] Estrella-Castillo DF, Gómez-de-Regil L. Quality of life in Mexican patients with primary neurological or musculoskeletal disabilities. Disability and health journal. 2016 Jan 1;9(1):127-33.

[22] Kaka B, Ogwumike OO, Adeniyi AF. Factors Associated with Health-related Quality of life among post-paralytic polio survivors in Nigeria. African Journal of Physiotherapy and Rehabilitation Sciences. 2011;3(1):17-22.

[23] Pawlowska-Cyprysiak K, Konarska M, ZolnierczykZreda D. Uwarunkowania Jakosci Zycia Osób Niepelnosprawnych Ruchowo. Determinants of quality of life of people with physical disability. Medycyna Pracy. 2013 Mar 1;64(2):227.

[24] Meulenkamp TM, Cardol M, van der Hoek LS, Francke AL, Rijken M. Participation of people with physical disabilities: three-year trend and potential for improvement. Archives of physical medicine and rehabilitation. 2013 May 1;94(5):944-50.

[25] Badenhorst M, Brown JC, Lambert MI, Van Mechelen W, Verhagen E. Quality of life among individuals with rugby-related spinal cord injuries in South Africa: a descriptive cross-sectional study. BMJ open. 2018 Jun 1;8(6):e020890.

[26] Paúl C, Ayis S, Ebrahim S. Disability and psychosocial outcomes in old age. Journal of Aging and Health. 2007 Oct;19(5):723-41.

[27] Barišin A, Benjak T, Vuletić G. Health-related quality of life of women with disabilities in relation to their employment status. Croatian medical journal. 2011 Aug 15;52(4):550-6.

[28] Tough, H., Siegrist, J. \& Fekete, C. Social relationships, mental health, and wellbeing in physical disability: Systematic review. BMC Public Health. (2017); 17, 414. doi:10.1186/s12889-017-4308-6

[29] Grist VL. Relationships between Age of Disability Onset, Adaptation to Disability, and Quality of Life Among Older Adults with Physical Disabilities. Florida: 2010; Florida State Libraries

[30] Barker, R.N., Kendall, M.D., Amsters, D.I., Pershouse, K.J., Haines T.P. \& Kuipers P. The relationship between quality of life and disability across the lifespan for people with spinal cord injury. Spinal Cord. 2009;47, 149-155. doi:10.1038/sc.2008.82 